\title{
Native grouper indirectly ameliorates the negative effects of invasive lionfish
}

\author{
Robert D. Ellis ${ }^{1,3, *}$, Meaghan E. Faletti ${ }^{2}$ \\ ${ }^{1}$ Florida State University, Department of Biological Science, Tallahassee, Florida 32306, USA \\ ${ }^{2}$ Florida Fish and Wildlife Conservation Commission, Division of Marine Fisheries Management, \\ 2950 Executive Center Circle East, Tallahassee, Florida 32301, USA
}

${ }^{3}$ Present address: Florida Fish and Wildlife Conservation Commission, Fish and Wildlife Research Institute, 100 8th Ave. SE, St. Petersburg, Florida 33701, USA

\begin{abstract}
Non-trophic interactions between Indo-Pacific lionfish Pterois volitans and P. miles and Atlantic and Caribbean reef fishes are not yet well understood. To determine the effects of potential competitive and behavioral interactions between native predators and invasive lionfish, we experimentally altered the presence of lionfish and red grouper Epinephelus morio in karst solution holes in Florida Bay, USA, and then tracked subsequent changes in the juvenile reef fish and motile macroinvertebrate communities for $6 \mathrm{wk}$. Relative to solution holes where we excluded both predators, mean juvenile reef fish abundance declined $83.7 \%$ in solution holes with a lionfish but increased by $154 \%$ in solution holes with a red grouper. There was no difference in juvenile reef fish abundance in solution holes with both lionfish and red grouper compared to holes where we excluded both predators. The composition of lionfish stomach contents shifted from mostly teleost fishes when lionfish were present in solution holes alone, to mostly crustaceans when in the presence of a red grouper. Concurrently, the abundance of 2 species of cleaner shrimp (Ancylomenes pedersoni and Periclimenes yucatanicus) decreased by $14.7 \%$ when lionfish were present but increased by $56.2 \%$ at holes where lionfish were excluded. We suggest that these results are due to altered lionfish predatory behavior in the presence of red grouper and highlight the importance of maintaining intact native predator communities for ameliorating the negative effects of the lionfish invasion.
\end{abstract}

KEY WORDS: Lionfish · Red grouper - Interspecific interactions · Community ecology · Reef fish · Invasive species $\cdot$ Ecological impacts

\section{INTRODUCTION}

A number of classic studies in ecology have shown the importance of predators in shaping the structure of prey communities across diverse marine ecosystems. More specifically, substantial evidence supports the ability of resident fish predators to affect the size and structure of reef fish communities via piscivory on post-settlement fish recruits (Hixon \& Beets 1993, Stallings 2009). These studies have largely focused on the direct interactions between predators and prey fish; however, predators

\footnotetext{
${ }^{*}$ Corresponding author: robert.ellis@myfwc.com
}

can also affect the size and structure of prey communities via indirect interactions. For example, predators can shape prey communities when they alter the traits or behaviors of intermediate species, a phenomenon commonly known as behaviorally mediated indirect interactions (BMIIs; Strauss 1991). Interaction chains driven by changes in the behavior or traits of intermediate species are often at least as strong as density-driven effects and may in fact account for the majority of predator effects on food chains (see reviews by Werner \& Peacor 2003 and Preisser et al. 2005).

(C) R.D.E. and the USA Government 2016. Open Access under Creative Commons by Attribution Licence. Use, distribution and reproduction are unrestricted. Authors and original publication must be credited.

Publisher: Inter-Research · www.int-res.com 
Among the studies to explicitly test piscivory-driven BMIIs, Stallings (2008) found a strong, positive effect of Nassau grouper Epinephelus striatus on the abundance of juvenile coral reef fishes in Bahamian patch reefs that was driven by changes in the foraging behavior of small-bodied groupers. Pusack (2013) investigated a similar interaction in which he found evidence for a BMII between Nassau grouper and juvenile coral reef fishes mediated by the behaviors of the lionfish Pterois volitans and P. miles, piscivores native to the Indo-Pacific and invasive in the western Atlantic and Caribbean since at least 1985 (Schofield 2009). Since about 2004, lionfish have experienced a rapid range expansion throughout the Caribbean, Gulf of Mexico, and southeastern US Atlantic waters and have been present on reefs in the Florida Keys, USA, since at least 2009 (Ruttenberg et al. 2012). As generalist predators, lionfish consume a diverse array of fishes and invertebrates (Valdez-Moreno et al. 2012, Côté et al. 2013a), and some evidence suggests an ontogenetic shift in diet where larger lionfish consume mostly fish (Morris \& Akins 2009). On invaded coral reefs, lionfish predation can reduce the abundance of native fishes by 80 to $94 \%$ and the biomass by up to $65 \%$ (Albins \& Hixon 2008, Green et al. 2012a, Albins 2013). By 2010 lionfish had invaded the hard bottom habitats of Florida Bay (see Fig. 1), which serves as an important nursery habitat for many fishes and invertebrates that move to nearby coral reefs as adults (Fourqurean \& Robblee 1999). Consequentially, predation by invasive lionfish in Florida Bay on juvenile coral reef fishes may have cascading consequences for the health of nearby coral reefs.

A common mesopredator resident in the hard bottom habitats of Florida Bay that will interact with invasive lionfish is the red grouper Epinephelus morio. In Florida Bay, red grouper are primarily associated with karst hard bottom features called solution holes - pockmarked pits in the limestone formed by past freshwater incursion - which they excavate by removing sediment and detritus (Coleman et al. 2010). Previous experiments conducted on the faunal communities associated with Florida Bay solution holes showed that red grouper presence positively affected the abundance and diversity of these communities and that the community-level effects were driven by strong interactions with only a small number of individual species from the total species pool (Ellis 2015). This group included some juvenile coral-reef fishes, primarily small juvenile grunts Haemulon spp., which were consistently among the most numerous fauna encountered in solution holes.
Red grouper consume primarily crustaceans and some demersal fishes (Moe 1969, Weaver 1996) and are territorial, making aggressive displays that include low frequency sound production and rapid direct approaches to conspecifics and other resident solution-hole fishes (Ellis 2015). These behaviors, combined with the fact that the red grouper is usually the largest individual animal encountered in solution holes, may displace or disrupt predation by resident and transient predators around solution holes. Over time, such behavioral interactions between red grouper and other piscivores could result in differential survival of post-settlement juvenile reef fish when compared to their survival in habitats without red grouper. This hypothetical BMII could be important in altering the predatory effects of lionfish that invade Florida Bay solution holes.

Several species of shrimp commonly found in Florida Bay solution holes, including Periclimenes yucatanicus, Ancylomenes pedersoni, and Stenopus hispidus, have been found in lionfish stomach contents (Morris et al. 2009, Faletti \& Ellis 2014). At least one of these species, A. pedersoni, is an experimentally verified cleaner that removes ectoparasites from reef fishes (Bunkley-Williams \& Williams 1998, McCammon et al. 2010). It is yet unknown how the presence of invasive lionfish may affect crustacean behaviors. Some shrimp species will change their behavior in the presence of finfish predators, often relying on habitat features for protection (Ory \& Thiel 2013). Two common species of anemones in Florida Bay, Condylactis gigantea and Bartholomea annulata, have symbiotic relationships with cleaner shrimp and may offer protection from predation for these species (Silbiger \& Childress 2008, Briones-Fourzán et al. 2012). Given that ectoparasites removed by cleaner shrimp can have negative and even lethal consequences for parasitized fish (Artim et al. 2015), lionfish predation on these species could represent another indirect negative effect on the native reef fishes in Florida Bay.

While other large-bodied groupers, including Nassau and tiger grouper Mycteroperca tigris, reportedly prey on lionfish (Maljković et al. 2008), red grouper apparently do not (Morris 2009). Mesocosm experiments have shown little effect of native grouper presence on lionfish behaviors (Morris 2009, Raymond et al. 2015). Furthermore, it has been widely debated whether mesopredators such as groupers actually function as biocontrol for invasive lionfish (see Mumby et al. 2011 and subsequent responses by Hackerott et al. 2013 and Valdivia et al. 2014). However, Pusack (2013) reported that Nassau grouper appeared to 
reduce the effect of lionfish predation on native reef fish abundance. As congeners, Nassau and red groupers are extremely similar in appearance and size. Given these similarities, we were motivated to investigate if a similar behavioral interaction may occur between lionfish and red grouper. To do this, we set up an experiment to test the potential BMII between red grouper and juvenile reef fish mediated through lionfish in Florida Bay solution holes. Here we present the results of an experiment designed to quantify (1) the effects of red grouper on solution hole-associated juvenile reef fish abundance and diversity; (2) the effects of lionfish on solution holeassociated juvenile reef fish abundance and diversity; and (3) the modification in lionfish effects on juvenile reef fish abundance and diversity in the presence of red grouper.

\section{MATERIALS AND METHODS}

\section{Study site}

Florida Bay is a large open embayment in south Florida bordered by the Florida Keys, the Everglades, and the Gulf of Mexico (Fig. 1). The benthic habitat of Florida Bay is primarily seagrass, interspersed with areas of karst hard bottom that is usually covered in a thin veneer of sediment and pockmarked with solution holes (Fourqurean et al. 2002). For this study, we used a set of 16 solution holes located in outer Florida Bay that were similar in terms of size and location (see Table S1 in the Supplement at www.int-res.com/articles/suppl/m558p267_supp.pdf). Solution hole area, defined here as the product of the 2 longest perpendicular measurements, ranged from 1.69 to $6.99 \mathrm{~m}^{2}$ (mean $\pm \mathrm{SE}: 4.20 \pm 0.371 \mathrm{~m}^{2}$ ). The maximum excavated depth of solution holes, defined here as the deepest single measurement taken within the excavated area of the solution hole, ranged from 26 to $77 \mathrm{~cm}(45.3 \pm 3.01 \mathrm{~cm})$.

\section{Experimental design}

To test the effects of lionfish on the abundance, diversity, and community structure of juvenile reef fish associated with solution holes in the presence and absence of red grouper, we conducted a 6 wk field experiment where we manipulated the presence of both red grouper and lionfish in solution holes. We first surveyed solution holes in early June 2013 to assess red grouper and lionfish presence. All solution holes were occupied by a red grouper, but no lionfish were present at any of the solution holes at the start of the experiment. We randomly assigned the 16 red grouperoccupied solution holes to one of 4 treatment groups (n = 4): (1) no predators; (2) lionfish alone; (3) red grouper alone; and (4) both lionfish and red grouper. Here we use the term 'no predators' to refer only to the absence of red grouper and lionfish in this treatment; we did not manipulate the abundance of any other native predators during the experiment. We used the 'no predator' treatment to estimate the effect of all other native predators (e.g. black grouper, toadfish, etc.) on solution hole communities. For the predator treatments, we used only a single lionfish or single red grouper to match the typical densities of these predators as observed in Florida Bay solution holes. Red grouper are generally solitary and often displayed territorial aggressive displays towards conspecifics (Ellis 2015). Lionfish densities in Florida Bay from 2010 to 2012 were similarly low and, despite an increase in occurrence over time, it was rare to encounter more than a single individual lionfish in a solution hole. We assumed that red grouper were unlikely to prey on lionfish but that red grouper presence would disrupt lionfish predation. This assumption allowed us to ignore any density-mediated indirect interactions (DMIIs) and just test for BMIIs be-

tween red grouper and the suite of so-
Fig. 1. Approximate locations of solution hole sites in southwest Florida Bay, USA, used in this study. Open stars: sites where we conducted experimental manipulations; closed stars: sites where we collected lionfish 
lution hole-associated juvenile coral reef fishes via lionfish. For the purposes of estimating the BMII between red grouper and juvenile reef fish via lionfish, the no predator treatment represents the baseline 'control' condition, the red grouper alone and lionfish alone treatments estimate the total effect of each predator separately on juvenile reef fish abundance, and the both predator treatment represents the 'threat' condition (sensu Okuyama \& Bolker 2007).

Red grouper present at the no predator and lionfish alone treatment holes were captured using hookand-line, measured for total length (TL), tagged with a dart tag, and released at a vacant solution hole located at least $5 \mathrm{~km}$ from the experimental study area. Previous experiments conducted in this system showed that relocating red grouper in this method was sufficient to prevent recolonization during the experiment (Ellis 2015). We collected 8 lionfish from hard bottom habitats located elsewhere in Florida Bay using monofilament hand nets, and then immediately transported them to the study area. Lionfish were measured and then individually released at each of the appropriate assigned lionfish alone or both predator solution holes. Lionfish are known to exhibit high site fidelity (Jud \& Layman 2012), so we did not expect them to migrate between solution holes during the study. The average size of lionfish used during the 2013 experiments was $17.4 \pm$ 0.89 (SE) cm TL, which corresponds to an age of 4-5 mo (Potts et al. 2011).

Prior to predator manipulations, a team of 2 divers on SCUBA conducted a visual census of all reef fishes associated with all 16 solution holes, following the methods described by Hixon \& Beets (1993). After slowly approaching the solution hole to a distance of $\sim 1 \mathrm{~m}$ from the edge, each diver slowly circled the hole while recording the number and identity of each fish species. Divers first focused on the active planktivores hovering above the hole, then enumerated and recorded any demersal and cryptic fishes and macroinvertebrates found inside the hole using flashlights to aid identification. Divers then summed their recorded abundances for each species and determined the average number per species. Total species richness was determined as the sum of all distinct species observed by both divers. Divers visually estimated the size of each fish to the nearest $1 \mathrm{~cm}$ (below $10 \mathrm{~cm} \mathrm{TL}$ ) or to the nearest $5 \mathrm{~cm}$ (above $10 \mathrm{~cm} \mathrm{TL}$ ). Each survey lasted until all individuals were counted, or for a minimum of $5 \mathrm{~min}$ (mean census duration was about $12 \mathrm{~min}$ ). The grunt species complex in Florida Bay contains at least 6 different species that are visually indistinguishable at sizes $<5 \mathrm{~cm} T \mathrm{TL}$, so grunts were identified to species when possible and individuals $<5 \mathrm{~cm}$ were grouped together as 'grunt recruits.' Divers also noted the identity and habitat association of cleaner shrimp. Specifically, divers noted if shrimp were found within $10 \mathrm{~cm}$ of either of the 2 anemones found in Florida Bay known to host cleaner shrimp (C. gigantea and B. annulata), or were found elsewhere in the solution hole not near anemones. This protocol was repeated weekly for $6 \mathrm{wk}$ ( 7 total surveys at each of the 16 solution holes). On average, it took $2 \mathrm{~d}$ to survey all 16 experimental solution holes.

In addition to conducting weekly diver censuses, we checked the no predator and lionfish alone treatment holes once every $48 \mathrm{~h}$ for the duration of the experiment to ensure that no new red grouper or lionfish had moved onto these sites. New individuals encountered were captured, measured, tagged, and released at unoccupied sites as described above. At the end of the experiment all lionfish were collected with hand nets and euthanized with an overdose of MS-222. We followed the methods described by Green et al. (2012b) for all lionfish dissections: first, we recorded lionfish total length and dry blotted weight, then removed and weighed the stomach, entire alimentary canal, and all stomach contents. We recorded the length and dry-blotted weight of all prey items before identifying prey to the lowest possible taxonomic group using guides from Humann \& Deloach (2002) for fishes and Abele \& Kim (1986) for crustaceans. Unrecognizable prey items were identified using undigested hard parts (e.g. otoliths, skeletons) whenever possible. Finally, we calculated the proportion of each prey group in the diet by number, size, weight, and frequency of occurrence.

\section{Statistical analysis}

We calculated a variety of community response variables to measure the effects of red grouper and lionfish separately and in concert on the native juvenile reef fish populations associated with solution holes: total abundance $(N)$, Hill's diversity numbers $H_{0}, H_{1}$, and $H_{2}$, and Hill's evenness $(E)$. Hill's numbers provide a means of calculating commonly used diversity indices using the single equation:

$$
H_{a}=\left(\sum_{i=1}^{S} p_{i}^{a}\right)^{\frac{1}{1-a}}
$$

where $p_{i}$ is the relative proportion of the community made up by species $i$ (Hill 1973). When evaluated for integer values for $a$ of 0,1 , and $2, H_{a}$ reduces to species richness, the antilog of the Shannon-Wiener 
index, and the reciprocal of the Simpson's index, respectfully. Generally, as a increases, the index gives greater weight to more abundant species. Hill's evenness, $E$, was calculated using the equation:

$$
E_{2,1}=H_{2} / H_{1}
$$

that Hill initially proposed because it does not include species richness $\left(H_{0}\right)$, and therefore is relatively insensitive to sample size (Hill 1997). Hill's evenness converges to 1 when all species are equally abundant, so smaller values indicate more uneven communities.

We used linear mixed-effects models (LMM) to draw inferences about the effects of predator treatment on the 5 community metrics $\left(N, H_{0}, H_{1}, H_{2}\right.$, and $E)$, following the methods described by Albins (2013). The models included 2 categorical explanatory variables, predator treatment and week, and a random intercept for each solution hole. Time (week) was included as a categorical variable to eliminate any assumptions about the relationship between response variables and time. Solution hole identity was included as a random variable due to the repeated measures design of the experiment that required multiple observations of the same hole across time. Model selection was based on likelihood-ratio tests (LRT) performed on nested models to determine if including a treatment by the week interaction term improved the model fit. Visual examination of the model residuals suggested violations of the assumptions of both homogeneity of variance and independence, so we fit alternative models for each community response metric: one that incorporated heteroscedasticity among treatments, one that incorporated temporal autocorrelation among observations within solution holes using the $A R(1)$ autoregression model, and one that incorporated both variance and autocorrelation structures. Because the addition of the variance and autocorrelation structures caused the models to be non-nested, the resulting model fits were compared with Akaike's information criterion (AIC) to determine the optimal model for hypothesis testing. $t$-tests were used to evaluate differences between all treatment contrasts for each of the 5 community response metrics at the end of the experiment, when the bestfit model from the LMM analysis indicated that predator treatment had a significant effect.

To evaluate the effects of red grouper and lionfish on the structure of the juvenile reef fish communities, we performed ordinations with non-metric multidimensional scaling (NMDS; McCune \& Grace 2002). For all ordinations, recruit abundances were squareroot transformed and standardized using the Wisconsin double standardization, where abundances were first standardized by species maxima and then by the sample total. We calculated Bray-Curtis distances for the ordinations and for hypothesis testing of recruit community structure and then tested for differences in the composition of recruit communities with permutational multivariate analysis of variance (PERMANOVA $_{i}$ Anderson 2001). Recruit abundances were not transformed or standardized, and all analyses were run with 1000 unconstrained permutations. Statistical analyses were conducted in the R software environment (R Core Team 2014) using the 'Ime4' package for the LMMs (Bates et al. 2015), and the 'MASS' and 'vegan' packages for the NMDS and PERMANOVA analysis (Venables \& Ripley 2002, Oksanen et al. 2011).

We estimated effect sizes for the direct effects of lionfish, the total indirect effects of red grouper, and the effects of both predators together on juvenile reef fish recruit abundance using a ratio-based approach (Trussell et al. 2006, Hughes et al. 2012). The direct effect (DE) of lionfish (LF) on recruit abundance, $R$, was calculated with the ratio of recruit abundance in the lionfish alone treatment to the mean recruit abundance in the no predator (NP) treatment:

$$
\mathrm{DE}_{\mathrm{LF}}=\left(R_{\mathrm{LF}} / R_{\mathrm{NP}}\right)-1
$$

Similarly, the indirect effect (IE) of red grouper on recruit abundance was calculated with the ratio of recruit abundance in the red grouper alone treatment (RG) to the mean recruit abundance in the no predator treatment:

$$
\mathrm{IE}_{\mathrm{RG}}=\left(R_{\mathrm{RG}} / R_{\mathrm{NP}}\right)-1
$$

Finally, the BMII of red grouper on recruit abundance via lionfish was calculated with the ratio of the recruit abundance with both predators (BP) (i.e. the effect of both predators or the lionfish effect in the presence of predator cues) to the mean recruit abundance in the lionfish alone treatment (following Okuyama \& Bolker 2007):

$$
\mathrm{BMII}=\left(R_{\mathrm{BP}} / R_{\mathrm{LF}}\right)-1
$$

The numerators for all ratios were provided by all replicates of the given treatment, whereas the denominator was the mean recruit abundance at the end of the experiment for the given treatment. We estimated means and $95 \%$ confidence intervals for all effect sizes by bootstrapping 1000 times with replacement to account for the low number of experimental replicates available for each of the treatments. This approach is similar to the methods used by Paine (1992) to quantify interaction strength.

In an earlier analysis, we found a relatively high 


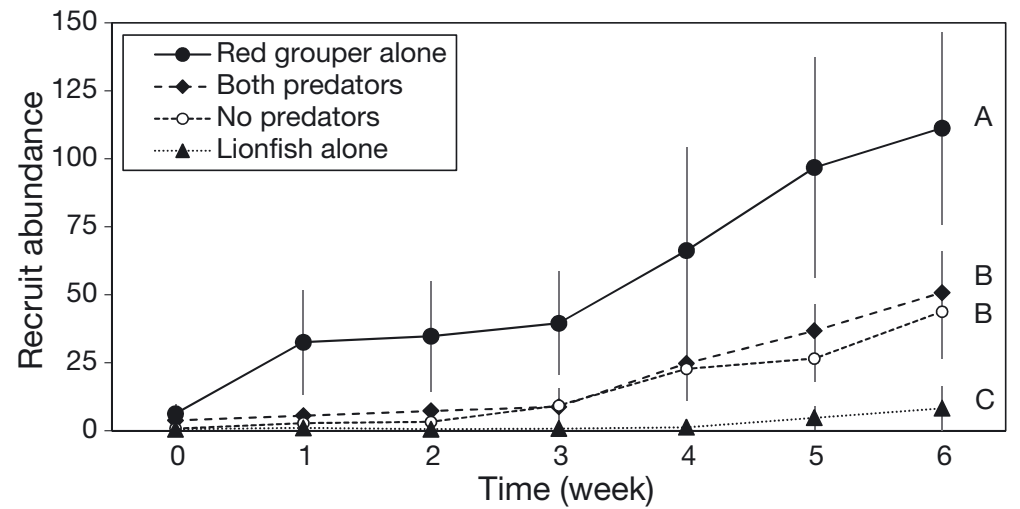

Fig. 2. Abundance (mean $\pm \mathrm{SE}$ ) of juvenile reef fish recruits at solution holes in Florida Bay from 4 experimental predator treatments $(n=4$ per predator treatment). Letters at the far right: results of pairwise comparisons among treatments at the final census; matching letters indicate $p>0.05$ based on pairwise $t$-tests performed on the best-fit linear mixedeffects model

Table 1. Estimated mean \pm SE of juvenile reef fish recruit community abundance, species richness, diversity, and evenness. p-values from pairwise $t$-tests performed on each of the 6 a priori contrasts based on the 5 community response variables at the end of the 6 wk experiment; $\mathrm{n}=4$ per predator treatment; ${ }^{*} \mathrm{p} \leq 0.1,{ }^{* *} \mathrm{p} \leq 0.05$. NP: no predator; LF: lionfish alone; RG: red grouper alone; BP: both predators

\begin{tabular}{|c|c|c|c|c|}
\hline Response & Treatment & Estimate & Contrast & $\mathrm{p}$ \\
\hline Abundance & $\begin{array}{l}\text { NP } \\
\text { LF } \\
\text { RG } \\
\text { BP }\end{array}$ & $\begin{array}{r}43.8 \pm 17.2 \\
8.25 \pm 8.25 \\
111 \pm 35.4 \\
50.8 \pm 15.2\end{array}$ & $\begin{array}{l}\text { NP vs. } \mathrm{LF}^{* *} \\
\text { NP vs. RG } \text { RG }^{* *} \\
\text { NP vs. BP } \\
\text { LF vs. RG } \text { RG* }^{* *} \\
\text { LF vs. } \mathrm{BP}^{* *} \\
\text { RG vs. } \mathrm{BP}^{*}\end{array}$ & $\begin{array}{l}0.037 \\
0.050 \\
0.413 \\
0.023 \\
0.027 \\
0.059\end{array}$ \\
\hline Species richness $\left(H_{0}\right)$ & $\begin{array}{l}\text { NP } \\
\text { LF } \\
\text { RG } \\
\text { BP }\end{array}$ & $\begin{array}{l}4.50 \pm 0.87 \\
1.00 \pm 1.00 \\
3.25 \pm 0.63 \\
5.75 \pm 0.63\end{array}$ & $\begin{array}{l}\text { NP vs. } L^{* *} \\
\text { NP vs. RG } \\
\text { NP vs. BP } \\
\text { LF vs. } \text { RG }^{* *} \\
\text { LF vs. } B^{* *} \\
\text { RG vs. } B^{* *}\end{array}$ & $\begin{array}{r}0.010 \\
0.148 \\
0.296 \\
0.014 \\
<0.001 \\
0.031\end{array}$ \\
\hline Shannon diversity $\left(H_{1}\right)$ & $\begin{array}{l}\left.H_{1}\right) \\
\text { NP } \\
\text { LF } \\
\text { RG } \\
\text { BP }\end{array}$ & $\begin{array}{l}2.78 \pm 0.17 \\
0.86 \pm 0.86 \\
2.30 \pm 0.41 \\
3.24 \pm 0.71\end{array}$ & $\begin{array}{l}\text { NP vs. } L^{*} \\
\text { NP vs. RG } \\
\text { NP vs. BP } \\
\text { LF vs. RG } \\
\text { LF vs. BP }{ }^{* *} \\
\text { RG vs. BP }\end{array}$ & $\begin{array}{l}0.059 \\
0.171 \\
0.448 \\
0.104 \\
0.033 \\
0.208\end{array}$ \\
\hline Simpson diversity $\left(H_{2}\right)$ & $\begin{array}{l}\text { NP } \\
\text { LF } \\
\text { RG } \\
\text { BP }\end{array}$ & $\begin{array}{l}2.25 \pm 0.08 \\
0.78 \pm 0.78 \\
2.09 \pm 0.41 \\
2.55 \pm 0.35\end{array}$ & $\begin{array}{l}\text { NP vs. } L^{*} \\
\text { NP vs. RG } \\
\text { NP vs. BP } \\
\text { LF vs. } R^{*} \\
\text { LF vs. BP* } \\
\text { RG vs. BP }\end{array}$ & $\begin{array}{l}0.077 \\
0.722 \\
0.470 \\
0.097 \\
0.053 \\
0.427\end{array}$ \\
\hline Evenness $\left(H_{2} / H_{1}\right)$ & $\begin{array}{l}\text { NP } \\
\text { LF } \\
\text { RG } \\
\text { BP }\end{array}$ & $\begin{array}{l}0.82 \pm 0.03 \\
0.22 \pm 0.22 \\
0.90 \pm 0.02 \\
0.80 \pm 0.03\end{array}$ & $\begin{array}{l}\text { NP vs. } \mathrm{LF}^{*} \\
\text { NP vs. } \mathrm{RG}^{*} \\
\text { NP vs. BP } \\
\text { LF vs. } \mathrm{RG}^{*} \\
\text { LF vs. } \mathrm{BP}^{*} \\
\text { RG vs. } \mathrm{BP}^{* *}\end{array}$ & $\begin{array}{l}0.080 \\
0.083 \\
0.663 \\
0.058 \\
0.086 \\
0.042\end{array}$ \\
\hline
\end{tabular}

proportion of decapod crustaceans in the stomach contents of lionfish collected from Florida Bay including some species known to provide cleaning services (Faletti \& Ellis 2014), so we were motivated to test for predator treatment effects on shrimp abundance using the LMM framework described above. When specific treatment effects were not found, we grouped treatments by lionfish presence - lionfish present (either alone or with a red grouper) and lionfish absent (no predators or red grouper alone) — and tested for differences in shrimp abundance between the start and end of the experiment using paired-sample $t$ tests. We tested for differences in cleaner shrimp habitat association between the start and end of the experiment and for differences in the fish to invertebrate ratio in lionfish stomach contents in the presence and absence of red grouper using a 2-tailed Fisher's exact test. We set the level of statistical significance for all tests at $\alpha=0.05$ and considered results to be marginally significant when $0.05<\mathrm{p} \leq 0.10$. Except when noted otherwise, all results are presented as means $\pm \mathrm{SE}$.

\section{RESULTS}

\section{Predator effects}

After 6 wk the abundance of juvenile reef fish recruits was greatest at solution holes with red grouper alone $(111 \pm 35.4)$, followed by holes with both predators (50.8 $\pm 15.2)$, and holes with neither predator $(43.8 \pm 17.2 ;$ Fig. 2). Of the 4 solution holes of the lionfish alone treatment, 3 had zero recruits present after $6 \mathrm{wk}$, while at the fourth we counted 33 recruits $(8.25 \pm 8.25)$. On average, the abundance of juvenile reef fish recruits at solution holes with both predators was significantly greater compared to the lionfish alone treatment and less than at the red grouper alone holes, but was not different from the no predator holes (Table 1). The results of LMM analysis supported including predator treatment either as a main effect or as an interaction with time for all metrics (see Table S2 in the Supplement). The preferred variance 

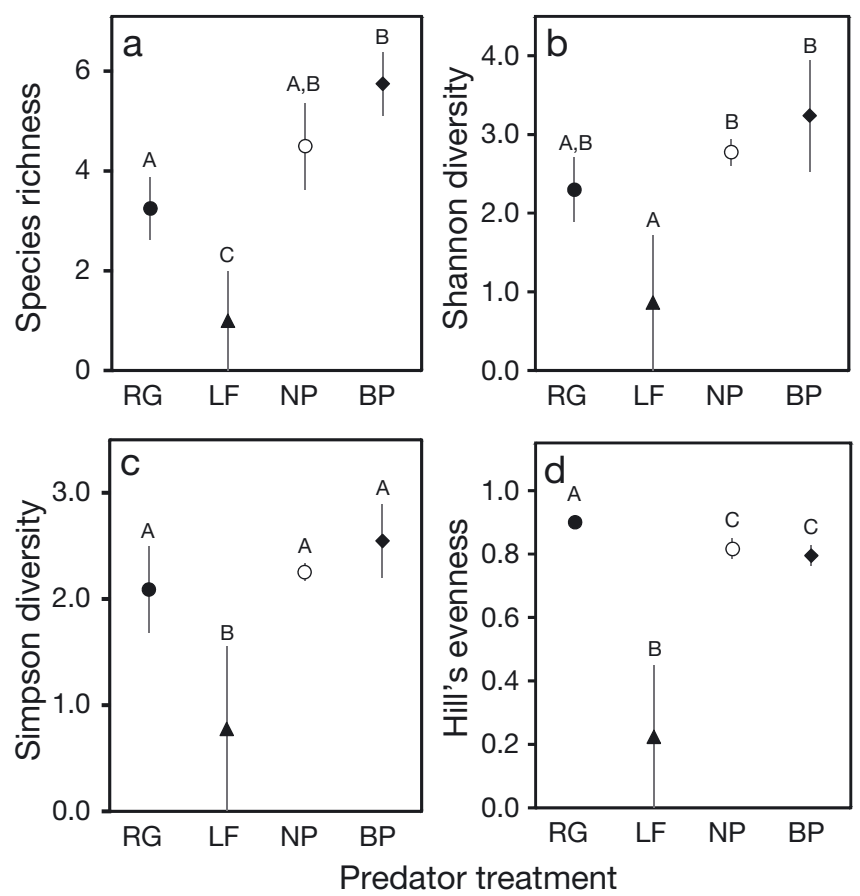

Fig. 3. (a) Species richness, (b) Shannon and (c) Simpson diversity, and (d) Hill's evenness of juvenile reef fish recruit communities after 6 wk with red grouper alone $\left(\mathrm{RG}_{;} \bullet\right.$ ), lionfish alone (LF; $\mathbf{\Lambda})$, no predator (NP; O), or both predators (BP; $\diamond) ; \mathrm{n}=4$ per predator treatment. Different letters indicate significant differences between groups after $6 \mathrm{wk}$ based on pairwise $t$-tests performed on the best-fit linear mixed model

structure and inclusion of temporal autocorrelation differed among the metrics tested, i.e. allowing variance to vary by treatment improved the models for abundance and evenness while including temporal autocorrelation improved the models for abundance and species richness.
Red grouper and lionfish had varying effects on the other community metrics when compared to the no predator holes. Red grouper alone had a marginally significant positive effect on the evenness of juvenile reef fish recruits compared to the no predator treatment (red grouper alone $=0.900 \pm 0.021$; no predators $=0.816 \pm 0.032 ; \mathrm{p}=0.083)$, but no other comparisons were significant (see Table 1). However, lionfish alone had a significant negative effect on all 5 of the community metrics tested compared to the no predator holes (Fig. 3). The species richness, Simpson's diversity, and evenness of juvenile reef fish communities were all significantly greater with red grouper compared to holes with lionfish alone. In general, communities were more species rich, diverse, and even with both predators compared to holes with lionfish alone (Fig. 3).

Compared to the no predator treatment, communities with both predators were not significantly different in terms of any of the community response metrics analyzed, including recruit abundance. However, we found a marginally significant difference between communities in the presence of both predators (5.75 \pm 0.63 recruit species) compared to those with red grouper alone $(3.25 \pm 0.63$ recruit species; $\mathrm{p}=$ 0.059), but these communities were significantly less even with both predators $(0.80 \pm 0.03)$ than they were with red grouper alone $(0.90 \pm 0.02 ; \mathrm{p}=0.042)$.

The structure of recruit communities varied greatly among predator treatments. During the $6 \mathrm{wk}$ experiment, we encountered 14 unique species of juvenile reef fishes. However, we counted only 9 of these species during the final survey at the end of the experiment (Table 2). Of this group, the grunts, specifically white and French grunts (Haemulon plumerii and $H$.

Table 2. Treatment effects, in terms of the relative difference in mean abundance of each of the 9 species encountered during the final (Week 6) survey and the full juvenile reef fish recruit community, for red grouper alone (RG), lionfish alone (LF), both predators together (BP), and the BMII estimate. Control values presented are the mean abundance of each species in the no predator (NP) treatment

\begin{tabular}{|c|c|c|c|c|c|c|}
\hline Species & Common name & $\begin{array}{c}\text { Control } \\
N_{\mathrm{NP}}\end{array}$ & $\begin{array}{l}\text { RG effect } \\
\left(N_{\mathrm{RG}}-N_{\mathrm{NP}}\right)\end{array}$ & $\begin{array}{l}\text { LF effect } \\
\left(N_{\mathrm{LF}}-N_{\mathrm{NP}}\right)\end{array}$ & $\begin{array}{l}\text { Combined effect } \\
\qquad\left(N_{\mathrm{BP}}-N_{\mathrm{NP}}\right)\end{array}$ & $\begin{array}{c}\text { BMII } \\
\left(N_{\mathrm{BP}}-N_{\mathrm{LF}}\right)\end{array}$ \\
\hline Haemulon plumierii & White grunt & 17.3 & 47.8 & -13.5 & 8.5 & 22.0 \\
\hline Haemulon flavolineatum & French grunt & 11.3 & 14.5 & -9.0 & 2.75 & 11.8 \\
\hline Haemulon spp. & Juvenile grunts & 11 & 7.75 & -9.5 & -4.5 & 5 \\
\hline Anisotremus virginicus & Porkfish & 0.25 & 0.25 & -0.25 & 0.5 & 0.75 \\
\hline Pomacanthus arcuatus & Gray angelfish & 0.0 & 0.0 & 0.0 & 0.75 & 0.75 \\
\hline Holacanthus ciliaris & Queen angelfish & 0.25 & -0.25 & -0.25 & 0.0 & 0.25 \\
\hline Haemulon parra & Sailors choice & 1.0 & -0.5 & -1.0 & 0.0 & 1.0 \\
\hline Lutjanus synagris & Lane snapper & 0.5 & -0.5 & -0.5 & -0.5 & 0.0 \\
\hline Pareques acuminatus & Highhat & 2 & -1.25 & -1.25 & -1.0 & 0.25 \\
\hline Total & & 43.5 & 67.8 & -35.3 & 6.5 & 41.8 \\
\hline$\%$ change & & - & 156 & -81.1 & 14.9 & 96.1 \\
\hline
\end{tabular}




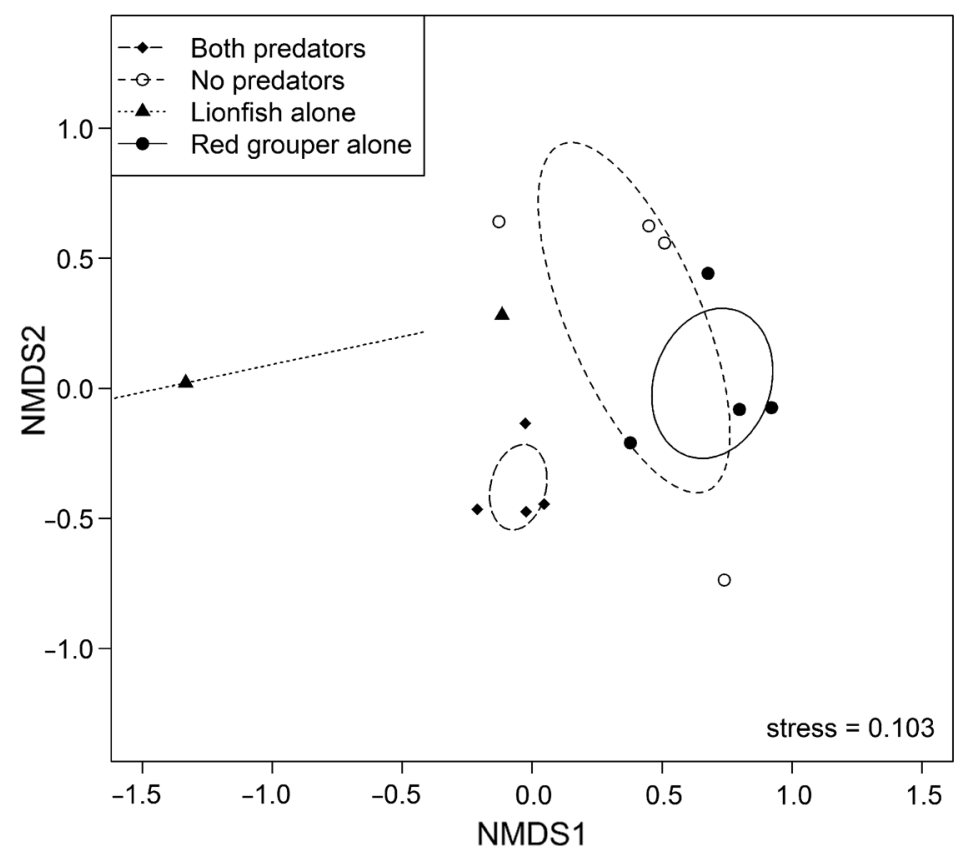

Fig. 4. Non-metric multidimensional scaling (NMDS) ordination of juvenile reef fish communities (abundance by species) associated with experimental solution holes at the end of the $6 \mathrm{wk}$ experiment conducted in Florida Bay during June-July, 2013. Ellipses show the $\mathrm{SD}$ of all points for each predator treatment group; $\mathrm{n}=4$ per predator treatment. No ellipse for the lionfish alone treatment as 3 of the 4 juvenile fish communities were non-existent $(n=0)$ at the end of the experiment; these sites are represented by the single point located at $(-1.33,0.0217)$

flavolineatum, respectively) were the most numerous. NMDS ordination of recruit communities showed clear separation of communities with lionfish (Fig. 4). However, because 3 of the 4 lionfish alone solution holes had zero recruits at the end of the experiment, the 3 zero-abundance points overlaid on top of each other (see point at $[-1.33,0.02]$ in Fig. 4), so the ellipse representing the standard deviation of the lionfish alone treatment communities collapsed to a line. There was significant overlap in the red grouper alone and no predator communities, while communities with both predators appeared to be separate from all other groups. PERMANOVA results indicated that predator treatment had a significant effect on community structure (pseudo- $F_{3,15}=2.27$, $p=0.029$ ), supporting the separation of communities by treatment visualized in the NMDS.

Overall lionfish alone reduced juvenile reef fish recruit abundance by $81.1 \%$ compared to the no predator treatment (Table 2). The bootstrapped estimate of the direct effect of lionfish on recruit abundance, calculated as the ratio of recruit abundance with lionfish to recruit abundance with no predators, was -0.802 (range: -1.00 to -0.434 ). The estimated indirect effect of red grouper alone on recruit abundance was 1.546 (range: 0.206-2.77), in line with the $156 \%$ increase in recruit abundance observed during the experiment. The estimated effect size of the BMII between red grouper and juvenile reef fish recruits via lionfish according to the ratio-based method was estimated as 5.18 (range: 2.15-8.73) or about 5 times the expected recruit abundance with lionfish alone.

After $6 \mathrm{wk}$, we found no effect of predator treatment on cleaner shrimp abundance. The LRT did not support including predator treatment in the final model for shrimp abundance (likelihood-ratio ${ }_{9,8}=0.77 ; \mathrm{p}=0.38$ ). However, the mean abundance of cleaner shrimp declined by $14.7 \%$ in solution holes with lionfish between the start and end of the experiment, irrespective of the presence or absence of red grouper. Conversely, mean cleaner shrimp abundance in solution holes without lionfish increased by $56.2 \%$, a marginally significant effect $(t=-2.23 ; \mathrm{p}=0.052$; Fig. 5). We also observed a significant shift in cleaner shrimp association with anemones in solution holes with lionfish, where $42.3 \%$ of cleaner shrimp were found within $10 \mathrm{~cm}$ of an anemone at the start of the experiment and $61.2 \%$ were within $10 \mathrm{~cm}$ of an anemone at the end of the experiment $(\mathrm{p}=0.011)$. In solution holes without lionfish, cleaner shrimp association with anemones did not significantly change $(p=0.89$; Fig. 6).

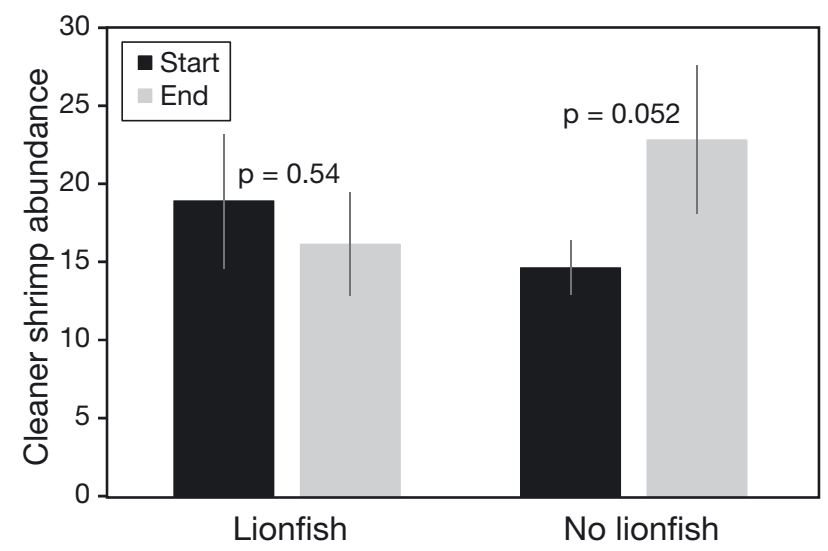

Fig. 5. Comparison between cleaner shrimp abundance (mean \pm SE) at the start and end of the experiment at solution holes with (lionfish alone + both predator treatments) and without (no predator + red grouper alone treatments) lionfish. pvalues reported above bars were based on paired $t$-tests comparing shrimp abundance at the start and end of the experiment for each group 


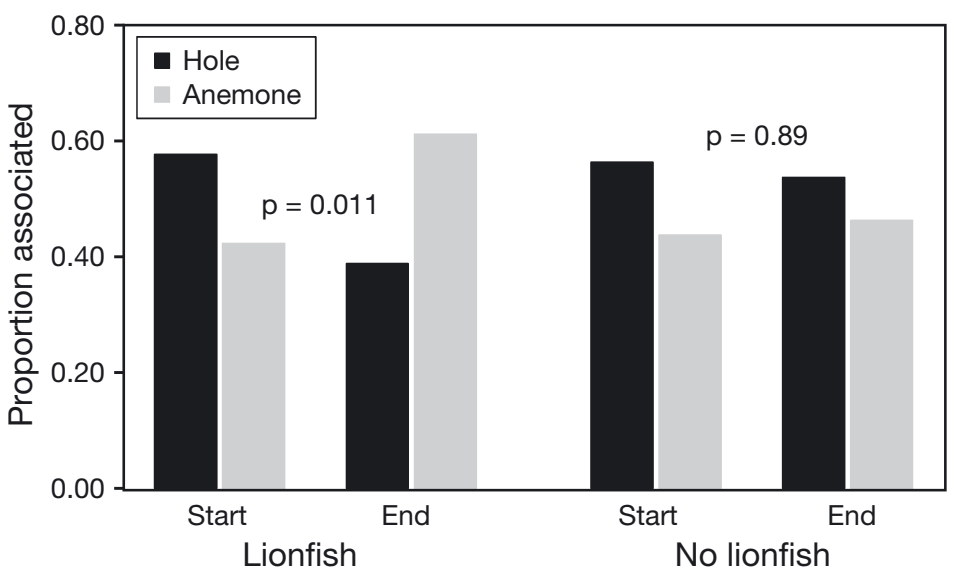

Fig. 6. Proportion of cleaner shrimp encountered on or within $10 \mathrm{~cm}$ of an anemone ('Anemone') or more than $10 \mathrm{~cm}$ from an anemone ('Hole') at the start versus the end of the experiment. Predator treatments were grouped by lionfish presence (lionfish alone + both predators treatments) or absence (no predator + red grouper alone treatments) in solution holes; $\mathrm{n}=8$ for each group. $\mathrm{p}$-values reported above bars are based on Fisher's exact test results comparing shrimp-anemone association at the start and end of the experiment for each group

\section{DISCUSSION}

The results of our experiment and diet analysis suggest that red grouper enhance the abundance of juvenile reef fishes that recruit to solution holes in Florida Bay and support the hypothesis that this effect occurs via changes in piscivore behavior in solution holes. Juvenile reef fishes benefited from the presence of the relatively large, territorial, habitat manipulating red grouper, while, conversely, recruit abundance was significantly depleted with lionfish. Lionfish are extremely efficient predators on Caribbean reef fishes, and reef fish populations on coral reefs and hard bottom habitats invaded by lionfish have suffered significant declines shortly following invasion (Albins \& Hixon 2008, Green et al. 2012a). The results presented here confirm that the negative effects of lionfish on native reef fish populations observed elsewhere in the invaded range

\section{Lionfish diet analysis}

Between June and August 2013 we analyzed the stomach contents of 29 lionfish captured at solution holes with $(\mathrm{n}=13)$ and without $(\mathrm{n}=16)$ red grouper. Overall, fish made up $51 \%$ of stomach contents by number and crustaceans made up $35.4 \%$, with the remaining $13.5 \%$ of prey items unidentifiable (see Table S3 in the Supplement). Mean gut content weight was $1.92 \pm 0.56 \mathrm{~g}$; only one stomach was empty. Palaemonid shrimps were the largest consumed family by number $(19.8 \%)$, while collectively cleaner shrimps (e.g. Lysmata spp., Ancylomenes pedersoni and Periclimenes yucatanicus) made up $30.1 \%$ of lionfish stomach contents. By weight, fish prey comprised $87.1 \%$ of lionfish stomach contents and crustaceans comprised $9.68 \% ; 3.23 \%$ of prey items by weight were unidentifiable. Within teleost prey groups, Lutjanids made up the largest percentage by weight $(34.2 \%)$, followed by unidentifiable teleosts $(22.3 \%)$, grunts (genus Haemulon; $16.4 \%$ ) and gobies (family Gobiidae; $9.43 \%$ ). We documented a shift in lionfish diet in the presence of red grouper from a primarily piscivorous diet when the lionfish were in solution holes alone to a crustacean-based one in holes when both lionfish and red grouper were present together $(p=0.028$; Fig. 7$)$. When alone, lionfish consumed $78.4 \%$ fish by number but fish prey made up just $43.4 \%$ of lionfish stomach contents when a red grouper was also present at the time of capture.

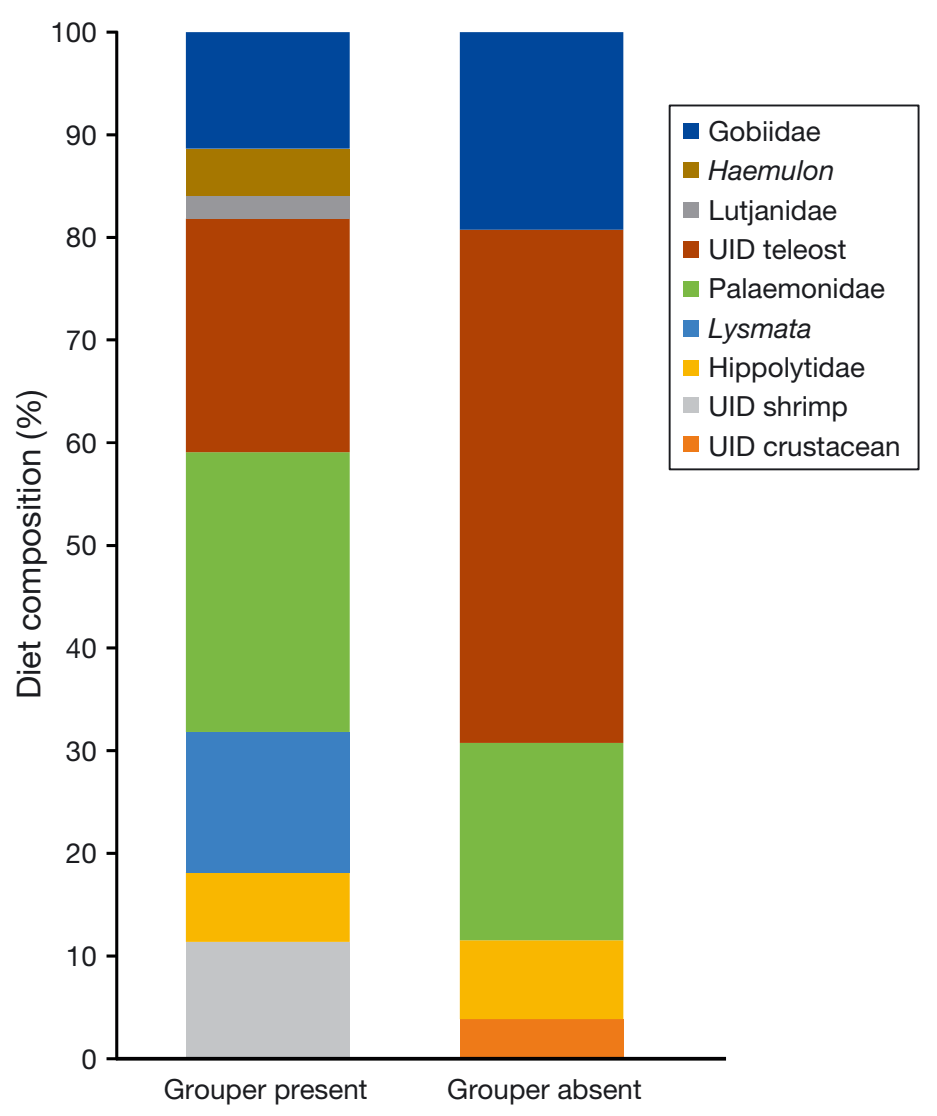

Fig. 7. Diet composition (\% by number) of lionfish collected from solution holes in Florida Bay with ('Grouper present') and without ('Grouper absent') a red grouper at the time of collection. UID: unidentifiable 
also hold true for Florida Bay hard bottom fish communities.

Lionfish and red grouper had very different effects on the diversity of juvenile reef fishes in Florida Bay solution holes. In general, solution holes with red grouper alone were similar to those with neither predator in terms of species richness and diversity. Meanwhile, similar comparisons are difficult to make for lionfish as they reduced recruitment to zero at 3 of the 4 lionfish-only treatment holes. While all 4 of the community diversity metrics were depressed in the lionfish alone treatment compared to the others, making specific conclusions about predator-driven effects on diversity are problematic when the predator leaves no prey at all. Certainly, this is a strong qualitative result if not a quantitative one: lionfish reduce the abundance and diversity of native Caribbean reef fishes, apparently through indiscriminate piscivory. Our results parallel those found in other parts of the invaded range including reductions in native reef fish recruitment (Albins \& Hixon 2008), reef fish abundance (Green et al. 2012a, Côté et al. 2013b), and species richness (Albins 2015).

We found no differences in recruit abundance in solution holes with both predators compared to the other treatments, and solution holes with both predators had comparable species richness and diversity compared to the red grouper alone and no predator treatments (see Table 1 ). These results generally support the BMII hypothesis: when red grouper were present in solution holes with lionfish, the associated communities of juvenile reef fishes, although depressed in abundance, were still similar to those in solution holes without red grouper or without either predator. Native fish communities appeared to benefit from the presence of red grouper compared to when the exotic piscivorous lionfish was present alone.

Our reevaluation of the diet composition of lionfish found in Florida Bay solution holes revealed that teleosts made up a smaller portion of the diet by number in Florida Bay compared to other diet studies done in the Bahamas and North Carolina (Morris et al. 2009, Munoz et al. 2011). We also found that gobies had the highest index of relative importance (IRI) of all prey groups, supporting reports elsewhere that gobies may be especially vulnerable to lionfish predation (Morris \& Akins 2009, Albins \& Lyons 2012). The shift we observed in diet from teleost-dominated to crustacean-dominated appeared to be driven by the presence of red grouper. This result further supports our BMII hypothesis that the disruptive presence of red grouper cause lionfish to alter their predation behavior to consume more benthic crustaceans that may be easier prey to consume compared to juvenile reef fish. Further investigation is needed to decipher the specific mechanisms driving this interaction. However, if lionfish alter their diets to target certain species such as cleaner shrimp, this could ultimately lead to a loss of the ecosystem services provided by those species. Larval settlement patterns for these 2 species in Florida Bay are unknown, though some other species of shrimps exhibit peaks of post larval settlement in the Middle Keys range of Florida Bay during the summer months (Criales et al. 2006). A summer influx of post larval shrimps could explain the increase in shrimp abundance we observed in the absence of lionfish throughout the study period.

Red grouper do not compete with lionfish for prey; although both will consume crustaceans and demersal fishes, the diets of lionfish collected from Florida Bay do not overlap with red grouper diets. However, we suspect that lionfish and red grouper may compete for space in solution holes. The exact nature of the lionfish response to red grouper, via modification of some specific behaviors by the lionfish or a more generally disruptive effect of red grouper presence, remains untested. The few studies that have explicitly investigated behavioral interactions between native Atlantic reef fishes and lionfish have found that lionfish generally ignore potential predators while native fish actively avoid the lionfish. One study of competitive shelter use between lionfish and Nassau grouper in experimental mesocosms found that Nassau grouper avoided lionfish even when they were much larger than the lionfish, but lionfish did not change their use of shelter even when the grouper was much larger (Raymond et al. 2015). During an experimental feeding trial, Morris (2009) reported that red grouper moved away from lionfish when approached. In the present study, we did not observe avoidance of lionfish by red grouper, or vice versa. However, the duration of such observations was limited to the time we spent conducting community censuses, and we did not quantify avoidance behaviors by either fish. Nevertheless, our results and those reported by Pusack (2013) suggest that invasive lionfish alter their feeding behaviors in the presence of larger native groupers.

The link between recruitment, post-settlement mortality, and adult population size for reef fish is complex. However, Shulman \& Ogden (1987) found that changes in immediate post-settlement survival of French grunts was a more important factor in regulating the ultimate abundance of adult grunts on 
coral reefs than to changes in recruitment. We tested the hypothesis that enhanced reef fish abundance at red grouper occupied solution holes results in part from disruptive behavioral interactions with piscivores that lead to enhanced survival of juvenile reef fishes. Importantly, we did not observe any predation on the transplanted lionfish during the experiment, despite reports elsewhere that groupers may act as predators of invasive lionfish (Maljković et al. 2008, Mumby et al. 2011). There are increasing control efforts across the invaded range, including attempts by spearfishers to 'teach' native groupers and sharks to feed on lionfish that have been largely unsuccessful and dangerous for divers (Diller et al. 2014). Ultimately, it may be that intact native fish communities that include native mesopredators are the best way to ameliorate the worst-case effects of lionfish by competing with and altering their behavior (Albins \& Hixon 2013). Some recent evidence suggests that Caribbean reefs with relatively high native predator density can maintain unchanged prey populations despite being invaded by lionfish (Elise et al. 2015). Other studies have found that lionfish-induced reductions in the density of native fishes $<10 \mathrm{~cm}$ TL did not translate to larger prey (10-20 cm TL; Albins 2015). Lionfish, then, may represent an enhanced gauntlet that juvenile reef fish must pass through, but not necessarily an impenetrable one.

The successful invasion of exotic species is thought to be more likely in human-altered ecosystems (Sax \& Brown 2000). As humans have reduced the biomass of native mesopredators on coral reefs and hard bottom habitats throughout the Caribbean, there are fewer competitive and behavioral interactions that limit both the population size and predatory effects of lionfish in its native range. The experiment presented here supports the mesopredator release hypothesis by showing how the presence of a native predator, the red grouper, can ameliorate the negative effects of lionfish predation on native reef fish communities. This study sheds some light on the community-level effects of both native and invasive predators, an integral part of expanding fisheries management from single-species stock assessments to ecosystem-based fisheries management (Pikitch et al. 2004). Here we show how an important fishery species, the red grouper, has complex direct and indirect interactions with the other species that colonize grouper-excavated solution holes in Florida Bay. Some of these interactions may have population-level effects on species that support fisheries and provide important ecosystem services, services that are lost or reduced by the presence of lionfish (Johnston et al. 2015).
Albins \& Hixon's (2013) description of a 'worst-case scenario' for lionfish in the western Atlantic highlights the need for intact predator communities to ameliorate the effects of the lionfish invasion. Our study provides some of the first experimental evidence of this effect and begins to shed light on the mechanisms by which native predators may lessen the negative effects of this exotic invader.

Acknowledgements. This project was conducted with permissions from the Florida Keys National Marine Sanctuary (permit \#FKNMS-2012-078), the Florida Fish and Wildlife Conservation Commission (SAL \#11-1330-SR), and the FSU Institutional Animal Care and Use Committee (IACUC Protocol \#1106). Financial support was provided by grants from the PADI Foundation, Florida Sea Grant, and the Guy Harvey Ocean Foundation to R.D.E. We thank C. Ellis, C. Malinowski, T. Richards, A. Schmidt, and M. Wilkerson for their assistance in the field. The FSU Coastal and Marine Laboratory provided valuable logistical support. Conversations with F. Coleman, M. Hixon, C. Koenig, and J. Wulff contributed significantly to the design of this work, while the manuscript benefited from comments by T. Miller, E. DuVal, M. Huettel, B. Inouye, and 3 anonymous reviewers. Finally, we thank the Gulf and Caribbean Fisheries Institute (GCFI) for their support of lionfish research and for a Travel Award to R.D.E. that enabled our participation at the $68^{\text {th }}$ GCFI in Panama.

\section{LITERATURE CITED}

Abele LG, Kim W (1986) An illustrated guide to the marine decapod crustaceans of Florida. Fla Dept Environ Reg Tech Ser, Vol 8. Florida State University, Tallahassee, FL

Albins MA (2013) Effects of invasive Pacific red lionfish Pterois volitans versus a native predator on Bahamian coral-reef fish communities. Biol Invasions 15:29-43

Albins MA (2015) Invasive Pacific lionfish Pterois volitans reduce abundance and species richness of native Bahamian coral-reef fishes. Mar Ecol Prog Ser 522:231-243

Albins MA, Hixon MA (2008) Invasive Indo-Pacific lionfish Pterois volitans reduce recruitment of Atlantic coral-reef fishes. Mar Ecol Prog Ser 367:233-238

Albins MA, Hixon MA (2013) Worst case scenario: potential long-term effects of invasive predatory lionfish (Pterois volitans) on Atlantic and Caribbean coral-reef communities. Environ Biol Fishes 96:1151-1157

Albins MA, Lyons PJ (2012) Invasive red lionfish Pterois volitans blow directed jets of water at prey fish. Mar Ecol Prog Ser 448:1-5

Anderson MJ (2001) A new method for non-parametric multivariate analysis of variance. Austral Ecol 26:32-46

Artim JM, Sellers JC, Sikkel PC (2015) Micropredation by gnathiid isopods on settlement-stage reef fish in the eastern Caribbean Sea. Bull Mar Sci 91:479-487

Bates D, Maechler M, Bolker B, Walker S (2015) Fitting linear mixed-effects models using lme4. J Stat Soft 67: $1-48$

Briones-Fourzán P, Pérez-Ortiz M, Negrete-Soto F, Barradas-Ortiz C, Lozano-Álvarez E (2012) Ecological traits of Caribbean sea anemones and symbiotic crustaceans. Mar Ecol Prog Ser 470:55-68 
Bunkley-Williams L, Williams EH (1998) Ability of Pederson cleaner shrimp to remove juveniles of the parasitic cymothoid isopod, Anilocra haemuli, from the host. Crustaceana 71:862-869

Coleman FC, Koenig CC, Scanlon KM, Heppell S, Heppell S, Miller MW (2010) Benthic habitat modification through excavation by red grouper, Epinephelus morio, in the northeastern Gulf of Mexico. The Open Fish Sci J 3:1-15

> Côté IM, Green SJ, Morris JA Jr, Akins JL, Steinke D (2013a) Diet richness of invasive Indo-Pacific lionfish revealed by DNA barcoding. Mar Ecol Prog Ser 472: 249-256

Côté IM, Green SJ, Hixon MA (2013b) Predatory fish invaders: insights from Indo-Pacific lionfish in the western Atlantic and Caribbean. Biol Conserv 164:50-61

Criales MM, Wang JD, Browder JA, Robblee MB, Jackson TL, Hittle C (2006) Variability in supply and cross-shelf transport of pink shrimp (Farfantepenaeus duorarum) postlarvae into western Florida Bay. Fish Bull (Wash DC) 104:60-74

Diller JL, Frazer TK, Jacoby CA (2014) Coping with the lionfish invasion: evidence that naïve, native predators can learn to help. J Exp Mar Biol Ecol 455:45-49

Elise S, Urbina-Barreto I, Boadas-Gil H, Galindo-Vivas M, Kulbicki M (2015) No detectable effect of lionfish (Pterois volitans and $P$. miles) invasion on a healthy reef fish assemblage in Archipelago Los Roques National Park, Venezuela. Mar Biol 162:319-330

Ellis RD (2015) Ecological effects of red grouper (Epinephelus morio) in Florida Bay. PhD dissertation, Florida State University, Tallahassee, FL

Faletti ME, Ellis RD (2014) Novel predator, novel habitat: a diet analysis and experimental test of the ecological effects of invasive lionfish in Florida Bay. Proc Gulf Caribb Fish Inst 66:217-221

Fourqurean JW, Robblee MB (1999) Florida Bay: a history of recent ecological changes. Estuaries 22:345-357

Fourqurean JW, Durako MJ, Hall MO, Hefty LN (2002) Seagrass distribution in South Florida: a multi-agency coordinated monitoring program. In: Porter JW, Porter KG (eds) The Everglades, Florida Bay, and coral reefs of the Florida Keys: an ecosystem sourcebook. CRC Press, Boca Raton, FL, p 497-522

Green SJ, Akins JL, Maljiković A, Côté IM (2012a) Invasive lionfish drive Atlantic coral reef fish declines. PLOS ONE $7: \mathrm{e} 32596$

Green SJ, Akins JL, Morris JA (2012b) Lionfish dissection: techniques and applications. NOAA Tech Memo NOS NCCOS 139

- Hackerott S, Valdivia A, Green SJ, Côté IM, Cox CE, Akins L, Bruno JF (2013) Native predators do not influence invasion success of Pacific lionfish on Caribbean reefs. PLOS ONE 8:e68259

Hill MO (1973) Diversity and evenness: a unifying notation and its consequences. Ecology 54:427-432

Hill MO (1997) An evenness statistic based on the abundance-weighted variance of species proportions. Oikos 79:413-416

Hixon MA, Beets JP (1993) Predation, prey refuges, and the structure of coral-reef fish assemblages. Ecol Monogr 63: 77-101

Hughes AR, Rooker K, Murdock M, Kimbro DL (2012) Predator cue and prey density interactively influence indirect effects on basal resources in intertidal oyster reefs. PLOS
ONE 7:e448d39

Humann P, Deloach N (2002) Reef fish identification: Florida, Caribbean, Bahamas. New World Publications, Jacksonville, FL

> Johnston MW, Purkis SJ, Dodge RE (2015) Measuring Bahamian lionfish impacts to marine ecological services using habitat equivalency analysis. Mar Biol 162: 2501-2512

> Jud ZR, Layman CA (2012) Site fidelity and movement patterns of invasive lionfish, Pterois spp., in a Florida estuary. J Exp Mar Biol Ecol 414-415:69-74

Maljković A, Van Leeuwen TE, Cove SN (2008) Predation on the invasive red lionfish, Pterois volitans (Pisces: Scorpaenidae), by native groupers in the Bahamas. Coral Reefs 27:501

McCammon A, Sikkel PC, Nemeth D (2010) Effects of three Caribbean cleaner shrimps on ectoparasitic monogeneans in a semi-natural environment. Coral Reefs 29: 419-426

McCune B, Grace JB (2002) Analysis of ecological communities. MjM Software Design, Gleneden Beach, OR

Moe MA (1969) Biology of the red grouper Epinephelus morio (Valenciennes) from the eastern Gulf of Mexico. Fla Dep Nat Resour Mar Res Lab Prof Pap Ser 10:1-5

Morris JA (2009) The biology and ecology of the invasive Indo-Pacific lionfish. PhD dissertation, North Carolina State University, Raleigh, NC

> Morris JA, Akins JL (2009) Feeding ecology of invasive lionfish (Pterois volitans) in the Bahamian archipelago. Environ Biol Fishes 86:389-398

Morris JA, Akins JL, Barse A, Cerino D and others (2009) Biology and ecology of the invasive lionfishes, Pterois miles and Pterois volitans. Proc Gulf Caribb Fish Inst 61: 409-414

Mumby PJ, Harborne AR, Brumbaugh DR (2011) Grouper as a natural biocontrol of invasive lionfish. PLOS ONE 6: e21510

> Muñoz RC, Currin CA, Whitfield PE (2011) Diet of invasive lionfish on hard bottom reefs of the Southeast USA: insights from stomach contents and stable isotopes. Mar Ecol Prog Ser 432:181-193

Oksanen J, Blanchet FG, Kindt R, Legendre P, O'Hara RB, Simpson GL, Wagner H (2011) vegan: community ecology package. R package version 1-17. https:/CRAN.Rproject.org/package=vegan

> Okuyama T, Bolker BM (2007) On qualitative measures of indirect interactions. Ecol Lett 10:264-271

> Ory NC, Thiel M (2013) Host-use patterns and factors influencing the choice between anemone and urchin hosts by a caridean shrimp. J Exp Mar Biol Ecol 449:85-92

Paine RT (1992) Food-web analysis through field measurement of per capita interaction strength. Nature 355: 73-75

Pikitch EK, Santora C, Babcock EA, Bakun A and others (2004) Ecosystem-based fishery management. Science 305:346-347

Potts JC, Berrane D, Morris JA (2011) Age and growth of lionfish from the Western North Atlantic. Proc Gulf Caribb Fish Inst 61:314

Preisser EL, Bolnick DI, Benard MF (2005) Scared to death? The effects of intimidation and consumption in predator-prey interactions. Ecology 86:501-509

Pusack TJ (2013) Coral-reef fishes: insights into larval dispersal and invasion ecology. PhD dissertation, Oregon State University, Corvallis, OR 
R Core Team (2014) R: a language and environment for statistical computing. R Foundation for Statistical Computing, Vienna. www.R-project.org

Raymond WW, Albins MA, Pusack TJ (2015) Competitive interactions for shelter between invasive Pacific red lionfish and native Nassau grouper. Environ Biol Fishes 98: $57-65$

Ruttenberg BI, Schofield PJ, Akins JL, Acosta A and others (2012) Rapid invasion of Indo-Pacific lionfishes (Pterois volitans and Pterois miles) in the Florida Keys, USA: evidence from multiple pre- and post-invasion data sets. Bull Mar Sci 88:1051-1059

Sax DF, Brown JH (2000) The paradox of invasion. Glob Ecol Biogeogr 9:363-371

Schofield PJ (2009) Geographic extent and chronology of the invasion of non-native lionfish (Pterois volitans [Linnaeus 1758] and $P$. miles [Bennett 1828]) in the Western North Atlantic and Caribbean Sea. Aquat Invasions 4: 473-479

Shulman MJ, Ogden JC (1987) What controls tropical reef fish populations: recruitment or mortality? An example in the Caribbean reef fish Haemulon flavolineatum. Mar Ecol Prog Ser 39:233-242

Silbiger NJ, Childress MJ (2008) Interspecific variation in anemone shrimp distribution and host selection in the Florida Keys (USA): implications for marine conservation. Bull Mar Sci 83:329-345

Editorial responsibility: Charles Birkeland, Honolulu, Hawaii, USA
Stallings CD (2008) Indirect effects of an exploited predator on recruitment of coral-reef fishes. Ecology 89:2090-2095

Stallings CD (2009) Predator identity and recruitment of coral-reef fishes: indirect effects of fishing. Mar Ecol Prog Ser 383:251-259

Strauss SY (1991) Indirect effects in community ecology: their definition, study and importance. Trends Ecol Evol 6:206-210

Trussell GC, Ewanchuk PJ, Matassa CM (2006) Habitat effects on the relative importance of trait- and densitymediated indirect interactions. Ecol Lett 9:1245-1252

> Valdez-Moreno M, Quintal-Lizama C, Gomez-Lozano R, Garcia-Rivas MC (2012) Monitoring an alien invasion: DNA barcoding and the identification of lionfish and their prey on coral reefs of the Mexican Caribbean. PLOS ONE 7:e36636

Valdivia A, Bruno JF, Cox CE, Hackerott S, Green SJ (2014) Re-examining the relationship between invasive lionfish and native grouper in the Caribbean. PeerJ 2:e348

Venables WN, Ripley BD (2002) Modern applied statistics with S, 4th edn. Springer, New York, NY

Weaver DC (1996) Feeding ecology and ecomorphology of three sea basses (pisces: Serranidae) in the Gulf of Mexico. MS thesis, University of Florida, Gainesville, FL

Werner EE, Peacor SD (2003) A review of trait-mediated indirect interactions in ecological communities. Ecology 84:1083-1100

Submitted: January 25, 2016; Accepted: June 17, 2016 Proofs received from author(s): August 15, 2016 